\title{
Mecanismo e organismo em Descartes, Kant e Schopenhauer: um breve estudo sobre a autonomia na formação da natureza
}

\author{
Mechanism and organism in Descartes, Kant and Schopenhauer: a \\ brief study on autonomy in the formation of nature
}

\section{Ana Carolina Soliva Soria*}

Universidade Federal de São Carlos, São Carlos, SP, Brasil

\section{Resumo}

A questão que norteia nossa análise é a de se a vontade Schopenhaueriana, como ímpeto formador de toda a natureza, não retomaria algumas ideias pré-críticas e pré-modernas de natureza. Para responder à essa questão, veremos como Descartes, ao mecanizar a natureza, confere-lhe uma autonomia frente a poderes externos que agem sobre ela a cada momento. Sua visão de mundo-máquina destoa, contudo, de suas ideias sobre a formação dos corpos vivos. O embrião põe para Descartes um problema que apenas séculos mais tarde será satisfatoriamente tratado por Kant. Este propõe que se julgue a natureza como mecânica ou como técnica e abre caminho para a solução encontrada por Schopenhauer, a saber: a vontade como impulso formador de toda a natureza.

* ACSS: Doutora em Filosofia, e-mail: anasoliva@ufscar.br 
Palavras-chave: Mecanismo. Organismo. Descartes. Kant. Schopenhauer.

\section{Abstract}

The question that guides our analysis is whether the Schopenhauerian will, as the forming force of all nature, would not return to some pre-critical and pre-modern ideas of nature. To answer this question, we shall see how Descartes, in mechanizing nature, gives it an autonomy in the face of external powers acting on it at every moment. His view of the machineworld, however, diverges from his ideas about the formation of living bodies. The embryo gives to Descartes a problem that only centuries later will be satisfactorily treated by Kant. He proposes that nature be judged as mechanical or technical and opens the way to the solution found by Schopenhauer, namely: will as the forming impulse of all nature.

Keywords: Mechanism. Organism. Descartes. Kant. Schopenhauer.

Segundo uma definição dada por Pichot em seu livro Histoire de la notion de vie, tanto em grego quanto em latim, a etimologia do termo natureza sugere uma ligação estreita dessa palavra com um caráter vivo do mundo. Ele escreve: "em latim, natura se liga a nasci, nascer; e em grego,

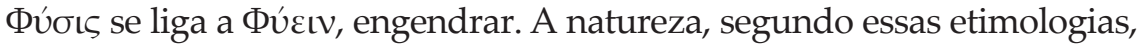
é primeiramente uma potência de engendramento, ao mesmo tempo em que é aquilo que é engendrado" (1993, p. 23, n. 9). Ainda segundo o autor, entendida em um sentido lato, a natureza na Antiguidade, na Idade Média e no Renascimento é uma potência de vida, isto é, de geração, de fazer brotar, de formação, potência esta dotada de uma espécie de alma (entendida, por exemplo, como primeiro motor ou como divindade), que agiria a todo o momento na natureza que ela anima, mas que não pode ser objeto de experiência alguma. Séculos mais tarde, Schopenhauer irá afirmar que a natureza é a manifestação da vontade e:

[...] a própria matéria é mera perceptibilidade dos fenômenos da vontade. Por isso, tem-se de reconhecer um querer em cada esforço que da natureza resulte em um ser material e que constitua propriamente 
essa natureza ou pela qual nesta se manifesta fenomenicamente (SCHOPENHAUER, 1986b, p. 407) ${ }^{1}$.

Mas como afirmar que toda a materialidade da natureza é manifestação da vontade sem entender por isso que há um poder de formação externo à natureza que a anima a partir de fora? Para respondermos à esta questão, acreditamos ser necessário analisar dois modos de se pensar a natureza, aqui representados por Descartes e Kant. Mais do que discutir pormenorizadamente a concepção de natureza em Schopenhauer, veremos como esses dois autores dão passos importantes para que o filósofo frankfurtiano afirme sua vontade na natureza, sem um retorno a modos de pensamento pré-críticos ou ainda pré-modernos. Sendo assim, veremos inicialmente como Descartes, ao criticar a noção de natureza que o precedia e mecanizá-la, desaminiza-a, na medida em que rompe com a ideia de alma como um princípio que age a cada momento sobre o vivente ou sobre o mundo. Examinaremos como, por um lado, Descartes perde a vivacidade da natureza, mas por outro, oferece um ganho frente aos autores que o antecedem: seu animal-máquina tem autonomia frente às influências externas e ocultas que pudessem agir sobre a sua organização e formação. Essa autonomia abre caminho para que, em seguida, um autor como Kant possa propor a ideia de organismo desprendida do mecanicismo e da instrumentalização que o antecedia. $\mathrm{O}$ orgânico será concebido juntamente com a questão da finitude do saber, ponto central de sua filosofia crítica. Por fim, apontaremos uma direção para se pensar como Kant abre espaço para que Schopenhauer possa, a partir de um ponto de vista crítico, recolocar a questão da natureza, sem, contudo, retomar modos de pensamento anteriores e pensá-la como dissociada do problema dos limites do conhecimento.

\section{Descartes e a concepção mecânica do mundo}

Em Métaphysique et biologie (2008, p. 21), Philippe Huneman escreve que nos séculos XVI e XVII a natureza era pensada como dividida

Tradução cotejada com a edição francesa (Cf. SCHOPENHAUER, 1996).

Rev. Filos., Aurora, Curitiba, v. 30, n. 49, p. 18-41, jan./abr. 2018 
em três reinos: o mineral, o animal e o vegetal. É curioso notar que Descartes não trata tão pormenorizadamente em seus textos das plantas; predomina em seus escritos o mineral (com a descrição da física geral feita em escritos como Tratado do mundo, Meteoros, Princípios) e do animal, mais especificamente, do homem (encontrado no Tratado do homem, Tratado das paixões, Descrição do corpo humano) (PICHOT, 1993, p. 342). Se podemos falar do reino vegetal em Descartes, este aparece predominantemente no funcionamento vegetativo do corpo humano e animal. O filósofo entende que os elementos que constituem os corpos - sejam eles mineral, vegetal ou animal - são de uma só substância, a saber: a extensa. Sendo assim, se Descartes considera em seus escritos a terra, o ar, o fogo etc., assim como a vida vegetativa e sensitiva, os três reinos compartilham, como afirmamos, uma só substância. O homem, como sabemos, é uma exceção a todo o restante da natureza, pois é o único que além da extensão (corpo) é dotado também da substância pensante (alma). Deixemos de lado a substância pensante a fim de entender a relação entre os princípios gerais da física e da fisiologia cartesiana (ou seja, a mecânica do movimento nos corpos em geral e no corpo vivo).

Para Descartes, tudo o que é do domínio da física, isto é, da natureza, é remetido ao corpóreo, ou seja, ao que é extenso. Todo corpo é extensão, e a extensão é, por sua vez, da alçada da geometria. A inteligibilidade do corpo não é definida em sua relação com a sensibilidade, mas com a racionalidade, já que o corpóreo, como extensão, é colocado no interior da geometria. E o corpo, sendo da competência da geometria, está sujeito à matematização do espaço. Todo corpo depende de uma verdade que é matemática, e o fundamento último desta verdade é, por sua vez, Deus que, sendo imutável, transfere a imutabilidade às próprias leis físicas. Há, portanto, em Descartes um claro delineamento das leis da natureza como necessárias e fixas, sem a intervenção de nenhum ser externo e oculto à própria natureza, assim como a impossibilidade de sua reconfiguração ou de qualquer poder criativo que aí pudesse se instalar. Descartes, ao desanimizar a natureza, subtrai-lhe também a vida entendida como potência de engendramento. Citamos um trecho do Tratado do mundo: 
Sabei, pois, primeiramente que por natureza não entendo aqui nenhuma deusa ou nenhum outro tipo de potência imaginária, mas que me sirvo dessa palavra para significar a matéria mesma, enquanto que a considero com todas as qualidades que lhe atribuí, compreendidas todas juntamente, e sob essa condição que Deus continua a conservá-la da mesma maneira que a criou; pois, somente a partir disso que continua assim a conservar, segue-se necessariamente que deve ter aí muitas mudanças em suas partes, que não podendo, me parece, ser propriamente atribuídas à ação de Deus, porque esta nada muda, eu as atribuo à natureza; e as regras segundo as quais se fazem essas mudanças, eu as nomeio leis da natureza (DESCARTES, 1824a, p. 253).

\section{A cosmologia cartesiana}

Sem a intervenção de uma "deusa" ou de qualquer outra "potência imaginária", para usarmos os termos do autor, a física cartesiana é o estudo da geometria do movimento dos corpos e do modo como esse movimento se transmite de um corpo a outro pelo choque. A natureza não conta assim com nenhum princípio motor externo a ela; o movimento é gerado pela ação mecânica de um corpo sobre o outro e ocupa um lugar privilegiado na física cartesiana, pois o movimento dos corpos não apenas institui uma autonomia no interior da natureza, mas é também uma espécie de princípio de individuação, de mudança dos corpos. Para melhor entendermos a relação do movimento com a possibilidade de mudança que se inscreve no interior da natureza, tomemos o que diz Descartes em sua teoria cosmológica.

Tal como lemos no Tratado do mundo, o universo é inicialmente composto de uma matéria extensa única, sólida e indefinida, que é dividida por Deus em partes de diferentes tamanhos: 1. Os que foram submetidos a uma quebra muito fina; 2 . Os que compõem fragmentos de grossura e peso intermediários; 3 . E os que ainda guardam algo da configuração original, de maior espessura e peso. No momento de quebra da matéria primeira, Deus impõe ao mundo um movimento e, consequentemente, esse movimento se transmite a todas as partículas que compõem o universo. O movimento perfeito é, segundo Descartes, o retilíneo uniforme - é o movimento primordial por excelência, que antecede 
todos os outros movimentos e todo desvio não é senão uma variação dele $^{2}$. Contudo, com o choque entre as partículas resultantes da quebra da matéria extensa primeira, os fragmentos se tornam arredondados e iniciam um movimento espiralado. Esse movimento é transmitido de um corpo a outro pelo choque entre as partículas, que mantém a quantidade de movimento imposta por Deus no ato de quebra da matéria primeira sempre constante. Para que qualquer partícula se desloque, é necessário que outra partícula ocupe o seu lugar, segundo um movimento também espiralado, em que substitui a posição da primeira, que marcha para frente, pelo da segunda, que ocupa o lugar da primeira.

O movimento espiralado, resultante do choque entre as partículas, permite a formação de um enorme turbilhão que separa as partes mais leves e agitadas, empurradas para o centro, das mais pesadas. As partículas centrais, devido a sua elevada agitação, compõem o sol. As mais pesadas se dividem por sua vez em duas partes: as de maior espessura são empurradas para as extremidades do turbilhão, formando os corpos sólidos (planetas) e as de menor espessura, que compõem o ar, são postas em uma posição intermediária entre o sol e os sólidos. No centro do turbilhão encontramos assim o sol, isto é, calor com produção de luz, em torno do qual gira todo o resto do universo, isto é, o transparente (ar) e os corpos opacos (sólidos). Quanto mais agitada a partícula, ou seja, quanto mais movimento ela realiza, maior é o calor que ela guarda consigo.

Devemos notar que para Descartes (1824a, p. 265) não há espaços vazios no universo. Entre as partículas, por mais pequenas e leves que sejam, há o que ele chama de "matéria sutil". A matéria sutil preserva a ideia de que o movimento somente pode ser transmitido de um corpo a outro pelo choque, isto é, que não se transmita a distância (tal como acontece na força gravitacional newtoniana). É pela força mecânica de uma partícula em relação a outra que a física cartesiana é pensada.

2 A esse respeito, escreve Pichot (1993, p. 313): “Uma tal mecânica, fundada sobre a inercia (ela mesma fundada sobre a constância de Deus) dá a primazia ao movimento retilíneo uniforme (e a justifica igualmente pela constância divina); este é o movimento por excelência, o movimento elementar, donde os outros não são mais do que variações (ou composições)". 
É importante notar que em Descartes, o movimento realizado pelos corpos não é entendido jamais de maneira absoluta. Ao contrário, o que temos é sempre o movimento de um corpo em relação a outro. Visto em sua totalidade, é como se o universo não se movesse, já que uma partícula deve ocupar o lugar da outra no movimento. Escreve Descartes no Tratado do mundo:

E como não se poderia fazer andar nenhuma parte de um tal corpo sem avançar também ou tirar do mesmo modo todas as outras, é necessário assim pensar que a ação ou a força de se mover ou de se dividir que foi posta primeiramente em algumas de suas partes é disseminada e distribuída em todas as outras ao mesmo instante tanto quanto poderia (DESCARTES, 1824a, p. 265).

Levantamos na primeira parte de nossa exposição o problema da cosmologia cartesiana por dois motivos: 1. Porque há nela uma evidente perda das causas finais na filosofia cartesiana. Os movimentos das partículas que compõem o universo, e consequentemente toda a física cartesiana, são pensados de maneira local, nunca de modo a formar uma unidade; Descartes não conta com nenhum plano anterior ou destino traçado previamente ao deslocamento pontual das partículas. O movimento se transmite por uma força mecânica de uma parte a outra, de tal modo que se perde toda possibilidade de um arranjo da totalidade da natureza. A mecânica cartesiana é assim incompatível com a articulação da natureza em uma unidade. Vale lembrar que o movimento, sendo sempre relativo, só pode ser pensado de maneira pontual, isto é, de parte a parte, e não levando em conta uma ordenação em que todo e parte se sustentassem mutuamente. 2. Porque o próprio corpo humano, como composto pelas mesmas partículas e pelas mesmas regras que constitui o universo, passa a ter uma configuração nos mesmos moldes da do cosmo, isto é, funciona tendo em vista os mesmos processos mecânicos. O movimento no corpo humano é produzido também pelo choque de uma parte sobre a outra, como veremos a seguir. 


\section{0 homem: alma, corpo e movimento}

Se o corpo humano para Descartes é extensão, está submetido às leis físicas que compõem toda a natureza. A essas leis exclui-se, certamente, a substância pensante. "Reconheço com evidência que nada há que me seja mais fácil de conhecer do que meu espírito" (DESCARTES, 1994, p. 136). Essas palavras que encerram a segunda das seis Meditações Metafísicas confirmam a verdade conquistada por Descartes parágrafos antes, a saber: o Cogito, e enunciam outra verdade: que o espírito é mais fácil de conhecer do que o corpo. Para o autor, a evidência primeira da essência e da existência da substância pensante dá a direção para a cadeia de deduções das demais verdades e dita a possibilidade de um conhecimento rigoroso da alma. Esse conhecimento é conquistado de modo independente do corpo. Na cadeia das representações claras e distintas, a substância extensa (o corpo) é secundária e derivada. Tal como podemos constatar nas Meditações, alcançamos o conhecimento da substância extensa apenas mediante uma dedução lógica rigorosa que parte do conhecimento da substância pensante, não sendo possível prosseguir em sentido inverso. A natureza da alma não pode ser apreendida e determinada pelas perturbações advindas do corpo, obscuras e confusas.

Para Descartes, se, por um lado não podemos traçar um paralelismo entre a substância extensa e a pensante, por outro, ambas as substâncias se encontram unidas de modo estreito e ininteligível. "União incompreensível”, escreve Granger, "pois mistura e confunde o divisível, que é extensão, com o indivisível, que é pensamento" (GRANGER, 1994, p. 25. cf. Sexta meditação, p. 194). A alma, não apenas alojada no corpo "como o piloto em seu navio" (DESCARTES, 1994, p. 189), está misturada a ele, e compõe com o corpo um todo. Sem semelhante mistura, não seríamos capazes de sensação alguma, dando-nos conta da fome, sede, dor etc. pelo entendimento, "como o piloto percebe pela vista se algo se rompe em seu navio" (DESCARTES, 1994, p. 190). As sensações que chegam ao espírito, uma vez que provêm e dependem da mistura das substâncias pensante e extensa (e não apenas da clareza e distinção da substância 
puramente pensante), são confusas e obscuras. Mas isso definitivamente não compromete a ordenação inscrita na natureza dos corpos: como toda substância extensa, o corpo humano se encontra submetido às leis físicas do movimento. Ao que nos parece, se há algo que poderia em Descartes dar uma totalidade orgânica ao corpo humano, esse algo seria a alma, que é una; contudo, uma vez que o corpo não se submete à clareza e distinção da alma, e sim às leis físicas dos choques entre as partículas, o corpo está condenado, tal como todo o restante do mundo, à ausência de qualquer princípio formador. A esse respeito, escreve Pichot:

Resumindo essa questão, para Descartes, a alma é apenas pensante; ela não contribui para a "formação" ["mise en forme"] do corpo. A única ação que ela pode exercer sobre esse corpo diz respeito aos movimentos voluntários [...], ainda que se veja com dificuldade como isso possa ser feito (PICHOT, 1993, p. 349).

Concebido como composto mecânico agitado por partículas, o corpo humano é comparado a um relógio ou autômato que tem no sistema circulatório sanguíneo a garantia de sua vida vegetativa e no coração, que aquece o sangue, o seu motor. Ao sistema sanguíneo liga-se o sistema hidráulico, aquele dos espíritos animais ${ }^{3}$. A agitação das partículas no coração é responsável pela agitação desses espíritos e pela circulação do sangue. Tudo o que escapa ao movimento voluntário e se refere à vida vegetativa escapa também à alma - nas palavras de Pichot (1993, p. 349): "a vida vegetativa é completamente 'desanimizada' e largamente mecanizada". As funções corpóreas estão submetidas às leis físicas e são concebidas mecanicamente, o que, por sua vez, concorda com a sua mecânica cosmológica (PICHOT, 1993, p. 305). E mesmo no movimento voluntário, a alma tem seus poderes limitados: é necessário que o corpo se encontre em um determinado estado para que se executem os movimentos pretendidos, os quais, diferentemente da alma, obedecem às leis do movimento, às quais ela deve se conformar.

Para Descartes, o cérebro filtra os espíritos animais contidos no sangue, guarda-os sob pressão, e os orienta para um determinado músculo. 
Do mesmo modo, o pensamento não é produzido no corpo, mediante a circulação dos espíritos e de sua matéria, mas apenas na alma.

A diferenciação feita por Descartes entre corpo e alma e a independência de ambos os funcionamentos não significa que a alma esteja sobreposta ao corpo como entidade distinta. Como dissemos, corpo e alma formam uma mistura. A mistura a que se refere Descartes na meditação sexta não nos autoriza, todavia, a pensar que a alma receba imediatamente a impressão das partes do corpo ou que ela age sobre ele. $\mathrm{O}$ vínculo entre o divisível e o indivisível, entre extensão e pensamento é feito por uma pequena parte do cérebro, "aquela onde se exerce a faculdade que chamam o senso comum, a qual, todas as vezes que está disposta da mesma maneira, faz o espírito sentir a mesma coisa" (DESCARTES, 1994, p. 195, grifo nosso). A capacidade da alma de experimentar as sensações advindas dos cinco sentidos e de unificá-las em uma só representação se funda sobre um "sexto sentido", que unifica os que o precedem. Essa faculdade, capaz de dar comunicabilidade às sensações provindas dos diferentes órgãos dos sentidos, é concebida como um órgão corporal, a saber: a glândula pineal. Se a alma está unida a todo o corpo, misturada a ele, não obstante, ela exerce todas as suas funções sobre uma parte determinada do corpo, qual seja: na glândula pineal. A alma se une ao corpo pelo sistema nervoso, responsável por filtrar os espíritos animais. Resume Descartes, em Da formação do feto:

[...] é o calor que ela [a máquina corporal] tem no coração que é como a grande mola [ressort] e o princípio de todos os movimentos que estão nela, e que as veias são os canos que conduzem o sangue de todas as partes do corpo para o coração, onde serve de alimento ao calor que aí está, como também o estômago e o intestino são outros canos ainda maiores, salpicados de muitos pequenos buracos por onde o extrato das carnes escoa nas veias, que o levam direto ao coração; e as artérias são ainda outros canos por onde o sangue, aquecido e rarefeito no coração, passa dali para todas as outras partes do corpo, as quais leva o calor e a matéria para nutri-las; e, enfim, as partes do sangue mais agitadas e vivas, sendo levadas ao cérebro pelas artérias que, de todas, vêm o mais em linha reta do coração, compõem como um ar ou vento muito sutil, que denominamos os espíritos animais, os quais, dilatando o cérebro, tornam-no próprio para receber as impressões dos objetos exteriores, e também aquelas da alma, isto é, para ser o órgão ou a sede do senso 
comum, da imaginação e da memória; depois, o mesmo ar ou os mesmos espíritos escoam do cérebro pelos nervos para todos os músculos, por meio do qual eles dispõem os nervos para servir de órgãos para os sentidos exteriores, e, inflando de modo diverso os músculos, dão o movimento a todos os membros (DESCARTES, 1824b, p. 435-36).

As leis mecânicas sobre as quais o filósofo francês fundamenta a compreensão do funcionamento do organismo humano subtrai, deste, todo princípio vital. Desanimizar a natureza é, ao mesmo tempo, desnaturar a natureza: essas considerações não podem nos levar a um julgamento errôneo acerca do pensamento de Descartes, a saber: ver nele um retrocesso em relação aos pensadores que o antecedem. Ao contrário, ao romper com a concepção de alma ou princípio vital externo ao próprio mundo, Descartes exclui de sua filosofia as virtudes ocultas pressupostas nas visões precedentes do vivente. A esse respeito, escreve Huneman:

Sublinhamos, entretanto, que o modelo mecânico, e, de modo mais abrangente, a compreensão mecanicista do vivente significam para aquele que é da medicina uma ruptura profunda com a compreensão medieval de que o corpo humano é fundamentalmente inteligível a partir das influências estrangeiras, em particular astrais, e das correspondências entre microcosmo-macrocosmo que regem a ordem do mundo. Por isso, o mecanicismo é um primeiro passo na afirmação da autonomia do vivente, ao menos do vivente que é o homem (HUNEMAN, 2008, p. 23-24, grifo nosso).

Se, por um lado, como afirma Huneman, é importante notar que não há um retrocesso em relação aos pensadores que o antecederam, por outro, devemos ressaltar que há um ganho significativo em relação a uma outra parte da teoria cartesiana do corpo humano, exatamente naquela que pode ser definida como problemática para o seu mecanicismo e, por isso mesmo, surpreendente, a saber: na formação do feto. Mesmo se Descartes não traz para primeiro plano em seus escritos o problema da geração e do crescimento das plantas ${ }^{4}$, não pode, contudo, ignorar o da gestação e do desenvolvimento do corpo humano. O filósofo evoca novamente os

4 Um dos exemplos da descrição do crescimento das plantas pode ser encontrado nos Princípios de filosofia, $4^{a}$ parte, § 201. 
princípios de sua cosmologia: na semente humana inicia-se um processo de fermentação que, tal como na da cerveja ou do vinho, produz calor. Esse calor que se dá no interior da semente cria um movimento circulatório ou vórtice que separa as partículas que irão compor cada parte do corpo. O primeiro órgão a ser formado a partir da circulação das partículas é o coração (fogo sem luz). O coração bombeia em linha reta o sangue para o que virá a ser a cabeça e, com isso, temos a formação do cérebro. A medula espinhal vem em seguida, e, posteriormente, o fígado.

Os comentadores concordam com o fato de que a formação do feto está em descompasso com o restante da teoria mecanicista de Descartes. Isso porque de acordo com os pressupostos desta teoria, o órgão é que dita a ação ou função por ele realizada. $O$ coração, por exemplo, dita a circulação sanguínea. A formação do órgão precede, assim, a sua ação ou função, e isso está inclusive de acordo com a exclusão de qualquer princípio misterioso que regeria o movimento dos corpos. Admitir o contrário, isto é, que a função precede a formação e a existência do órgão, é contrariar os pressupostos básicos da mecânica do movimento. Ou melhor, é admitir que deve haver uma ordenação prévia na concepção humana e, consequentemente, na formação do cosmo e em toda a natureza. O que a formação do feto traz à luz é uma contradição, ou, para usarmos uma palavra menos polêmica, um problema para o interior do próprio pensamento de Descartes: ao escrever que a circulação precede a existência do coração e dos vasos, afirma-se que a função destes órgãos precede sua feitura. Instaura-se, então, a dúvida: a formação do feto implica a admissão de uma "mise en forme" da natureza? Haveria uma auto-organização da matéria no crescimento e desenvolvimento da semente? Aqui entramos em um tema negligenciado da filosofia cartesiana, pois, tal como afirma Pichot:

Todo esse aspecto da biologia cartesiana é um pouco negligenciado em geral pois não corresponde com a ideia que fazemos do corpo como um autômato mecânico. Aqui, com efeito, o mecanicismo não concerne ao funcionamento de um órgão dado, mas à constituição do órgão; e essa constituição, ao menos para o sistema sanguíneo (que é o arquétipo do modelo mecânico cartesiano), faz-se a partir da função: é a circulação de fluidos que cria os vasos que vão, em seguida, canalizá-la. Não é 
mais o órgão que produz a função (o sistema vascular e sua bomba que produz a circulação); é a função que produz o órgão (a circulação de fluidos que, inicialmente, cria o coração, que facilita o crescimento dessa circulação, e os vasos, que a canalizam; a partir do que se constituem os outros órgãos por "filtrações diversas"). Em Descartes, toda função é quase remetida a um movimento de fluido, com ou sem filtração e depósito de matéria; não é, pois, excessivo dizer que nessa embriologia, é realmente a função, ou antes, o funcionamento, que produz o órgão, embora o próprio Descartes não empregue essa fórmula (PICHOT, 1993, p. 381-82).

Exemplo bastante utilizado para se compreender a fisiologia mecanicista é, como vimos, a comparação do corpo com um autômato ou com um relógio. No entanto, ao inverter a ideia de que o órgão deve preceder a função, a embriologia permite que se coloque a questão do relojoeiro ou do fabricante do autômato. Em seus escritos, Descartes não pode desconsiderar o fato de que Deus deve ser visto como um artífice de toda a natureza. Mesmo o funcionamento do órgão sendo mecânico, deve-se pressupor um artesão que calcula a função antes mesmo da feitura do órgão. Nesse caso também teríamos a pressuposição de algo que contraria a fisiologia mecanicista. Mas como agiria esse artífice? Sabemos que Descartes não pode fazer apelo a nenhuma deusa ou potência imaginária na natureza, ideia já apresentada. A questão permanece, até onde entendemos, em aberto. Nas palavras de Descartes:

Dirão com desdém que é ridículo atribuir um fenômeno tão importante quanto a formação do homem a causas tão pequenas; mas seria necessário, pois, causas maiores do que as leis eternas da natureza? Quer-se a intervenção imediata de uma inteligência? Do próprio Deus? Por que nasce, pois, monstros? Quer-se ver aí a operação dessa deusa da natureza muito sábia que deve sua origem apenas à extravagância do espírito humano? (DESCARTES apud PICHOT, 1993, p. 384).

$\mathrm{O}$ apelo a qualquer força misteriosa na natureza e, como vimos anteriormente, à própria alma, está vedado ao filósofo francês. Tal como entendemos, Descartes parece ter deparado com um problema crucial acerca da geração dos corpos vivos e da concepção de organismo. Por mais que ele tenha observado a formação de galinhas em diferentes 
estágios do desenvolvimento, segundo Jacques Roger (1993, p. 145), a demonstração mecanicista de sua formação, "sobre o plano dos princípios", era necessária. Contudo, "sobre o plano dos fatos", ou ainda, do ponto de vista empírico, não era muito satisfatória. Tomando a imagem do relógio como paradigma para se pensar o corpo vivo, há de se levar em conta que o relógio não produz outro relógio, e que é necessário fazer referência a um relojoeiro que constrói a máquina e pensa as suas funções. Se Descartes deu um passo importante para a autonomia do vivente em relação às forças externas que nele agiriam, faltaria reformular ao problema da finalidade interna e compreender a impossibilidade de submetê-la, em sua totalidade, a leis e demonstrações universais. Kant dará um importante passo nessa direção, como veremos a seguir.

\section{Kant e a concepção de organismo}

Mas como resolver a questão da formação dos corpos orgânicos sem fazer apelo a uma força misteriosa que atuaria na natureza e retira dela a sua autonomia. Passemos agora para Kant: O que é modificado, afinal, com ele? Qual o passo definitivo para a concepção de uma técnica oposta ao mecanismo? Tal como nos afirma Lebrun em Kant e o fim da metafísica, a originalidade de Kant não está em expulsar da natureza a ideia de mecanismo. A consideração kantiana da natureza exige um modo de explicação ou representação antinatural. Kant não abandona completamente o artificialismo da natureza, e esse artificialismo fará referência ainda a termos da concepção mecânica como causa e efeito. Contudo, as relações mecânicas não são o único modo pelo qual se pode julgar a natureza. Tal como afirma Kant na primeira introdução à Crítica do Juízo:

Pode perfeitamente subsistir, lado a lado, que a explicação de um fenômeno, que é uma operação da razão segundo princípios objetivos, seja mecânica; e que a regra do julgamento desse mesmo objeto, porém, segundo princípios subjetivos da reflexão sobre ele, seja técnica (KANT, 1995, p. 54). 
Kant refere-se a duas diferentes maneiras de se julgar o objeto que não são excludentes: uma mecânica e outra técnica. A primeira, capaz de explicar um fenômeno, traz sob conceitos as coisas naturais - há, nesse caso, uma determinação do fenômeno no uso das categorias. Nesse sentido, se tomarmos o corpo humano ou um corpo qualquer (terra, pedras, minerais) ambos podem ser vistos como massas quantificáveis, mensuráveis em suas partes e das quais se é possível chegar a um conhecimento universal. A segunda, ao contrário, não dá conceitos e, consequentemente, não indica nenhum uso da razão segundo princípios objetivos, mas sim subjetivos. Não se pode, nessa segunda maneira de julgar, dar à natureza nenhum conceito determinado, ou ainda, torná-la objeto suficientemente apreensível pela ciência. Sem fazer apelo a qualquer força misteriosa que atue na natureza a partir de seu exterior e que retire dela sua autonomia, Kant afirma que os corpos podem ser julgados como não estando subsumidos às leis universais determinadas, mas a princípios universais, indeterminados, de uma ordenação final da natureza em um sistema. Com isso, temos um sentido para a natureza que escapa ao conhecimento, que vai além dele. $\mathrm{O}$ vínculo encontrado para esse viés de investigação do natural estaria, segundo o filósofo, num acordo interno ou conveniência entre o diverso. Escreve Kant,

Dessa maneira, vemos terras, pedras, minerais, e coisas semelhantes, sem nenhuma forma final, como meros agregados, contudo tão aparentados segundo seus caracteres internos e os fundamentos-de-conhecimento de sua possibilidade, que são aptos a entrar sob leis empíricas para a classificação das coisas em um sistema da natureza, sem, contudo, mostrar uma forma do sistema em si mesmo (KANT, 1995, p. 53).

Entendido desse modo, o julgamento pressupõe a existência de uma natureza que não é dada pelas categorias, mas segundo leis empíricas que, tal como um correspondente das categorias, seriam capazes de trabalhar com o heterogêneo. Dito de outro modo, o que Kant nos expõe na primeira introdução à Crítica do Juízo é que as categorias, no esforço de encontrar leis universais para os fenômenos, conceitualiza, destrói o heterogêneo. A determinação objetiva é assim a abstração de toda diversidade de leis empíricas possíveis - nela, leva-se em conta 
apenas as condições de possibilidade da experiência em geral. Ao dissolver a heterogeneidade, as categorias podem apenas estabelecer relações limitadas e fixas, tal como Descartes fez com toda a natureza. A unilateralidade da mecanização está, assim, em determinar tudo objetivamente, isto é, em buscar leis sem considerar a diversidade do empírico. Com isso, perde-se a possibilidade de uma ordenação orgânica da natureza. Tudo é pensado tal como a união de um agregado, de uma máquina. O sentido para o qual o juízo reflexionante aponta é outro, a saber: que a natureza especifica suas leis universais em empíricas, em conformidade com a forma de um sistema. Esse ponto alcançado apenas pela faculdade de julgar conduz a uma comunidade entre o diverso, sem que se perca a heterogeneidade. Encontra-se aí um princípio da experiência não determinado, ou, nas palavras de Kant, uma pressuposição transcendental subjetivamente necessária. Contando apenas com o entendimento, não é possível encontrar a diversidade de leis empíricas. Somente o juízo ao qual compete trazer as leis particulares pode encontrar a afinidade entre leis particulares contingentes.

O que falta à concepção teórica do entendimento é, assim, a de um fim natural que organiza a natureza em um sistema. Tal como afirma Kant no § 78 da Crítica do Juízo:

Mas o certo é que ele [o mecanismo] será sempre insuficiente para as coisas que chegamos a reconhecer como fins naturais, por mais longe que o levemos. Por isso teremos que subordinar todos aqueles princípios a um princípio teleológico de acordo com a constituição do nosso entendimento. Ora, aqui se funda a legitimidade e - por causa da importância que o estudo da natureza possui para o nosso uso teórico da razão segundo princípio do mecanismo - também a obrigação de explicar pelo mecanismo todos os produtos e acontecimento da natureza, mesmo os mais conformes a fins e tão longe quanto estiver na nossa capacidade (cujos limites não podemos indicar no âmbito deste tipo de investigação). Mas então nunca se deve perder de vista que temos que por fim subordinar aquelas coisas à causalidade segundo fins, coisas essas que só podemos apresentar à própria investigação sob o conceito de fim da razão, de acordo com a constituição essencial da nossa razão e não obstante aquelas causas mecânicas (KANT, 2005, p. 256). 
O que a Crítica do Juízo nos ensina é que há um limite para o âmbito restrito do entendimento e que esse próprio limite acabaria por indicar, em certa medida, a necessidade de se pensar a natureza de um outro modo que amplia e complementa a maneira que o entendimento a compreende. Nesse sentido, é da constatação mesma de certo limite do juízo teórico que a Crítica do Juízo pode mostrar a legitimidade do juízo teleológico, como se o próprio mecanicismo pressupusesse a consideração, em seu limite, da natureza como um sistema a partir de um juízo teleológico ou técnico.

Se fosse possível determinar objetivamente a ideia de sistema ou fim natural, se ao invés de atuar o juízo reflexionante, entrasse em cena o determinante para se alcançar a totalidade da natureza, se pudéssemos dar uma objetividade a isso, teríamos então a ciência da concordância interna entre o heterogêneo. Contudo, dessa impossibilidade, o acordo entre o caráter interno do diverso só pode se dar em um como se. Nesse sentido, o ramo de erva não pode ser determinado objetivamente (tal como se faz no uso mecânico do entendimento). Quando a planta é tomada como objeto de uma ciência (a botânica), objeto de um conhecimento determinado, de conceitos, cai-se em uma concepção mecânica, desnaturada, desse objeto. A planta, julgada de um ponto de vista técnico, não se determina por conceitos. Podemos colocar assim a problemática questão: Seria essa concordância interna que permite a Kant afirmar que o animal é uma planta cujas raízes estão no estômago e que a planta é um animal cujo estômago está na raiz? Isto é, afirmar que a planta está em analogia com o animal e o animal com a planta? Ou ainda, tal como afirma Kant na Antropologia, que o "sono, como relaxamento de todas as faculdades de percepção externa e principalmente de movimentos voluntários, parece necessário a todos os animais, mesmo às plantas (segundo a analogia destas últimas com os primeiros para se recobrar as forças utilizadas quando se está acordado)" (KANT, 2006, p. 74).

Reconhecemos na planta algo da totalidade não determinada da natureza. Totalidade essa que não podemos ter experiência, pois trata-se de uma ideia da razão. Quando reconhecemos na planta essa totalidade, julgamos a natureza como se houvesse um fim, o qual, por sua vez, é pressuposto, mas não determinado objetivamente. Da impossibilidade de se encontrar a causa determinada e ativa de uma obra da natureza, recorre-se a uma 
analogia com o produto da arte, a um como se fosse o produto intencional de um entendimento. Se não podemos encontrar nenhuma intencionalidade nos corpos organizados, isso não nos impede de pensá-los (pensar, mas não conhecer!) como se fossem feitos segundo uma finalidade intencional. "Não há organismo-máquina", escreve Lebrun, "sem a presença de um engenheiro" (LEBRUN, 2002, p. 334), a intencionalidade deste na feitura da máquina jamais pode ser demonstrada.

Voltemos à questão já colocada acerca da aproximação entre mecânico e orgânico. O orgânico é aproximado do artificial, e a imagem da fabricação torna-se indispensável para a compreensão do organismo (como recurso para se pensar a sua causa). Kant põe a solução em uma analogia; analogia esta que limita a própria possibilidade de solução para esse problema. Nas palavras de Lebrun (2002, p. 349): "Os fenômenos só devem ser explicados enquanto são dadas na experiência as condições de sua explicação, e a relação de um organismo ao Criador é tão pouco dada quanto o Todo absoluto do mundo".

Se Kant não pode solucionar o problema da relação causal (e consequentemente da origem) do organismo porque os elementos para isso não são dados na experiência, isso não o impede de constatar algo evidente (ou seja, do qual pode ter experiência): que no organismo "tudo é reciprocamente meio e fim" (LEBRUN, 2002, p. 349). Com isso, a noção instrumentalizada do órgão tal como concebida, como vimos, por Descartes, isto é, de que o fim a que estava destinado está inscrito em seu exterior, é pulverizada, uma vez que o meio e o fim correspondem reciprocamente. A destinação de um órgão e o seu funcionamento ou atuação são para Kant indissociáveis.

Kant conta com uma constatação (a da reciprocidade meio-fim) para pensar o que do organismo não pode ser dado empiricamente, a saber: a precedência do todo em relação às partes. (Problema que, como vimos, já estaria na Formação do feto.) Esse fato não pode ser dado na experiência, contudo, a experiência não deve ser um obstáculo para a compreensão do organismo. $\mathrm{O}$ feto de Descartes seria assim o grande predecessor da concepção do organismo? Quanto a isso, podemos dizer que foi Kant que pôs às claras, quem disseminou a ideia de unidade sistemática. Foi ele, e não Descartes, quem foi lido, relido, estudado pelos autores do século XIX. A 
ideia de que há uma relação recíproca entre meio e fim, e que se deve pressupor uma totalidade que produza suas partes e que se ponha como princípio de causalidade devemos a Kant. Admite-se com isso um fim. Para não se ferir os princípios do entendimento, a causalidade deve ser pensada como intencional. Por outro lado, isso possibilita uma descontinuidade entre orgânico e inorgânico, já que o primeiro não pode ser apreendido em sua totalidade pelos princípios da possibilidade da experiência, ao passo que o inorgânico se subordina a esses princípios.

\section{Schopenhauer, organismo e vontade}

Schopenhauer não irá discordar de Kant no que diz respeito a esses dois modos de se tomar a natureza, a saber: segundo a homogeneidade ou heterogeneidade de suas relações. No parágrafo 23 do Mundo como vontade e representação, o autor se refere ao inorgânico como sendo aquele em que as relações de causa e efeito se dão de modo direto e evidente, e podem ser traduzidas em leis universais e necessárias. O exemplo mais alto desse modo de relação é o do movimento transmitido pelo choque entre duas bolas. Quanto maior a intensidade da causa, tanto maior será o seu efeito. O grau de uniformidade e homogeneidade da relação causal é, nesse caso, máximo, e, consequentemente, a intervenção do heterogêneo é mínima. $\mathrm{O}$ cálculo de determinação da natureza inorgânica nos evidencia que nela não há individualidade alguma. Os eventos submetidos a leis universais e necessárias podem ser repetidos mecânica e infinitamente, obtendo-se sempre os mesmos resultados.

[...] na causa genuína, o efeito cresce exatamente na mesma proporção que a causa, que é a mesma da reação; assim, se o modo de ação é conhecido, o grau do efeito é medido e calculado pelo grau de intensidade da causa, e também o inverso. Essas causas propriamente ditas agem em todos os fenômenos da mecânica, da química etc., sucintamente: em todas as modificações dos corpos inorgânicos (SCHOPENHAUER, 1986a, p. 177). 
Mas conforme passamos do inorgânico para o orgânico, é possível ver que a natureza dá aí um salto: a especificidade dos corpos organizados está em que a proporção da relação causal deixa de poder ser determinada com um cálculo preciso. Perde-se, com isso, a possibilidade de serem determinados segundo leis universais e necessárias, pois há em seus eventos a intromissão de fatores heterogêneos. Schopenhauer fará referência a uma individualidade progressivamente crescente nos corpos orgânicos, a saber: em menor grau nas plantas, em grau intermediário nos animais (devido à presença do entendimento) e em grau máximo nos homens (dotado de entendimento e razão). As faculdades de conhecimento intuitivo e abstrato tornam a relação entre ação e reação progressivamente complexa, impedindo que calculemos exatamente o modo como causa e efeito se enlaçam. Não há, nesses casos, possibilidade de uma ciência exata. Escreve ele:

[...] chamo excitação aquela causa que não sofre nenhuma reação que corresponda à sua própria ação, e cuja intensidade não se move de modo algum paralelamente ao grau de intensidade do efeito, que não pode, por consequência, tornar-se medida. [...] Todo efeito sobre um corpo organizado é desse tipo (SCHOPENHAUER, 1986a, p. 177).

Não queremos afirmar com isso que os corpos orgânicos não podem ser conhecidos em suas relações mecânicas, isto é, segundo leis tomadas universalmente. O deslocamento da linfa no interior das plantas pode ser pensado aos moldes de um sistema hidráulico e suas capilaridades. Isso permite calcular com alguma precisão e apreender a natureza conceitualmente, contudo, subtraímos mediante essa legislação toda possibilidade da heterogeneidade da natureza. Nesse caso, ela nada mais é do que algo análogo à teoria do movimento pelo choque.

Mas se Schopenhauer e Kant concordam quanto a isso, os dois modos de se tomar a natureza não serão postos pelo primeiro em termos de juízo determinante ou reflexionante. Se, como afirmamos, em Kant a determinação objetiva é feita com a abstração de toda diversidade de leis empíricas, em Schopenhauer, a identificação entre objeto e representação coloca o problema em outros termos. Cacciola expõe bem a questão: 
Se objeto (Gegenstand) e representação são uma e mesma coisa, nesse sentido, poderíamos dizer que qualquer representação é um objeto, porém sem qualquer garantia da objetividade no sentido kantiano, isto é, sem o que Kant chama de determinação de objeto, propiciada pelas categorias, ou conceitos puros. Qual seria pois o critério que permitiria falar de um objeto para o conhecimento? Nada mais do que a representação, o fato de ser um objeto para um sujeito. No entanto, isso não dá o critério de "realidade", de ser algo além do conhecimento subjetivo, pois a faculdade de entendimento do sujeito que elabora esse conhecimento intuitivo ao aplicar a causalidade à sensação, transferindo a sua causa ao espaço, e transformando-a num objeto externo. Por isso, o mundo é minha representação, e não de um sujeito transcendental (CACCIOLA, 2015, p. 34).

A questão da objetividade desloca-se para o da realidade: se podemos falar da natureza em termos mecânicos ou orgânicos, o critério de realidade dos objetos naturais não poderá estar no âmbito da própria representação, e esta, sendo sinônimo de objeto. Como é sabido entre os comentadores, Schopenhauer irá dar positividade à coisa em si negativamente tratada por Kant. E esta positividade será encontrada em um elemento interior à própria experiência do sujeito, qual seja: a vontade. $\mathrm{O}$ ponto central de sua argumentação recai sobre o corpo. $\mathrm{O}$ caminho da representação não nos leva senão a becos sem saída. O corpo é a intersecção entre a experiência interna e externa; como experiência externa a nós mesmos, ele é mero objeto para um sujeito, ou ainda, mera representação. E na medida em que é apenas objeto, não pode fundar a objetividade das representações. Mas tomado em suas ações, ou ainda, como algo externo às formas que condicionam a representação, ele é o querer viver ou a vontade. E essa duplicidade do corpo não se restringe apenas ao corpo próprio, mas a toda a natureza.

Se o juízo reflexionante em Kant complementava o ponto de vista do juízo determinante, em Schopenhauer, o ponto de vista da vontade completa o da representação. Mas aqui encontramos mais uma divergência: a chave para se chegar à vontade não está no uso da razão segundo princípios subjetivos. Aliás, a razão nada mais faz do que fixar o conhecimento vindo da experiência e comunicá-lo. A objetividade de uma representação não depende dela. A organização da natureza 
em uma totalidade não poderá vir da razão, mas apenas da vontade. E a vontade cabe à metafísica, que parte da experiência do corpo em ação para chegar a outra metade do mundo. Ao lado da ciência, que trabalha com representações abstratas, coloca-se imprescindivelmente a metafísica. Mas não uma metafísica que faz apelo a forças misteriosas que fundamentaria ou seria causa da natureza a partir de algo externo à intuição. Com a impossibilidade de se atribuir causalidade à vontade (pois esta está fora das formas que condicionam a representação), podemos afirmar que é ela (e não um fim natural dado pela razão) que dá unidade e significação para a representação, porque esta, submetida ao espaço, tempo e causalidade, está infinitamente dividida em partes. Para além da razão, do entendimento e das formas da representação, a vontade é a costura das partes, e a conservação da parte no todo e do todo na parte. A essa reciprocidade Schopenhauer denomina organismo. Unidade e particularidade não podem subsistir separadamente. $\mathrm{O}$ problema colocado pelo texto da formação do feto retorna na filosofia schopenhaueriana: do ponto de vista da vontade, não há como se pensar uma dissociação e precedência das partes em relação à ação que o corpo realiza, seja este orgânico ou inorgânico.

Não submetida ao espaço, ao tempo e à causalidade, a vontade como ímpeto cego e formador de toda a natureza está dada inteiramente em cada ato corporal. Vontade e atividade não podem ser dissociadas. Aqui encontramos a marca do limite da representação e da finitude do saber humano que filia Schopenhauer à filosofia crítica (Cf. CACCIOLA, 1981 e 1994). E assim como não há um retorno a uma filosofia pré-crítica, o autor do Mundo também não retoma modos de pensamento pré-modernos, pois sua filosofia não extrapola os limites da experiência e do próprio mundo. A autonomia da natureza está, assim, assegurada. Nas palavras de Cacciola:

Como imanente é o que se revela como complementar ao conhecimento científico da natureza, que apresenta limites além dos quais não pode se aventurar. Mas se dissermos que a metafísica ao ultrapassar tais limites, chega a um outro território que está além da experiência, vemos que essa afirmação é a única fonte da metafísica. A metafísica se coloca num outro ponto de observação dessa mesma experiência, diverso do 
da ciência, para explicá-la sem recorrer ao suprassensível. Se se trata de um outro ponto de vista, ou de um outro nível, este só pode se referir a um outro tipo de conhecimento a que se chega de modo diverso, não do exterior ao mundo, mas partindo do seu âmago, das forças que o movem e do impulso que as põem em ação. Não de um olho que de fora do mundo o observa, mas um olho que se forma no mundo para que ele se veja a si mesmo (CACCIOLA, 2015, p. 41-42).

\section{Referências}

CACCIOLA, M. L. M. O. A Crítica da Razão no Pensamento de Schopenhauer. Dissertação (Mestrado em Filosofia) - São Paulo, Universidade de São Paulo, 1981.

CACCIOLA, M. L. M. O. Schopenhauer e a Questão do Dogmatismo. São Paulo: Edusp, 1994.

CACCIOLA, M. L. M. A filosofia da natureza em Schopenhauer. In: BULHÕES, F.; LEITE, C. N.; SILVA, M. F. Natureza e metafísica: atas do IV Colóquio Internacional de Metafísica. Natal: EDUFRN, 2015.

DESCARTES, R. Traité du monde. Oeuvres de Descartes. Paris: F. G. Levrault, 1824a. t. IV.

DESCARTES, R. De la formation du fœetus. Oeuvres de Descartes. Paris: F. G. Levrault, 1824b. t. IV.

DESCARTES, R. Meditações metafísicas. In: Obras escolhidas. Rio de Janeiro: Bertrand Brasil, 1994.

DESCARTES, R. Princípios da filosofia. Lisboa: Edições 70, 1997.

GRANGER, G. G. Introdução. In: DESCARTES, R. Obras escolhidas. Rio de Janeiro: Bertrand Brasil, 1994.

HUNEMAN, P. Métaphysique et biologie. Paris: Éditions Kimé, 2008.

KANT, I. Duas introduções à Crítica do Juízo. São Paulo: Iluminuras, 1995.

KANT, I. Crítica da faculdade do Juízo. Rio de Janeiro: Forense-Universitária, 2005. 
KANT, I. Antropologia de um ponto de vista pragmático. São Paulo: Iluminuras, 2006.

LEBRUN, G. Kant e o Fim da Metafísica. Trad. Carlos Aberto Ribeiro de Moura. São Paulo: Martins Fontes, 2002.

PICHOT, A. Histoire de la notion de vie. Paris : Gallimard, 1993.

ROGER, J. Les sciences de la vie dans la pensée française au XVIIIe siècle. Paris : Albin Michel, 1993.

SCHOPENHAUER, A. „Die Welt als Wille und Vorstellung“. In: Sämtliche Werke in fünf Bänden. v. I. Stuttgart/Frankfurt am Main : Suhrkamp, 1986a.

SCHOPENHAUER, A. „Über den Wille in der Natur“. In: Sämtliche Werke in fünf Bänden. v. III. Stuttgart/Frankfurt am Main : Suhrkamp, 1986b.

SCHOPENHAUER, A. De la volonté dans la nature. Paris : Quadrige / PUF, 1996.

Recebido: $21 / 01 / 2018$

Received: 01/21/2018

Aprovado: 05/02/2018

Approved: 02/05/2018 